\title{
Assessment of Nurses Knowledge Toward Neonate with Birth Asphyxia at Neonatal Intensive Care Unit in Pediatric Hospitals at Babylon Governorate
}

\author{
Salim Amir Yousef ${ }^{1}$, Abdul Mahdi Abdul Ridah Hasan² \\ ${ }^{1}$ Post Graduate Student in Pediatric Nursing, Babylon Health Directorate, Iraq, ${ }^{2}$ A. Prof. phD in Pediatric \\ Nursing, College of Nursing/ University of Babylon - Iraq
}

\begin{abstract}
Background: Birth asphyxia is neonates' inability to activate and sustain breathing at conception .. It is also recognized as a condition that arises when blood gas delivery is compromised, contributing to hypoxemia and hypercapnia The combination of hypoxia and ischemia may contribute to a cascade of biochemical changes in the body contributing to neuronal brain loss and brain harm

Objectives: In order the aim of study to Identify the demographic characteristic of sample , Identify knowledge of nurses in caring of neonate with birth asphyxia at NICU at pediatric hospitals in Babylon governorate, determine the relationship between nurses knowledge with birth asphyxia at NICU with certain of socio- demographic characteristics of sample Babylon, Iraq.

Methodology: A comprehensive research is undertaken to investigate nurses' understanding of Neonate with Birth Asphyxia in the Neonatal Intensive Care Unit at Babylon Governorate Pediatric Hospitals A randomized random sample of (62) nurse is chosen with the usage of the chance sampling method. The research group is spread in the Neonatal Intensive Care Unit at Babylon Governorate Pediatric Hospitals. The data was obtained using a built-in self-report questionnaire and evaluated using the concise statistical analysis method that involves "frequencies \& percentages" and the Inferential statistical data analysis methodology used for the Chi-square test.
\end{abstract}

Results: Results of the analysis show that the participants with excellent awareness served (66.1 percent), whereas those with bad information (33.9 percent) reflected nurses in the Neonatal Intensive Care Unit at the Babylon Governorate Pediatric Hospitals. In comparison, the mean age of experienced nurses is 32.73 \pm 9.33 while those with bad awareness are $26.05 \pm 5.86$. Significant linkages exist between Education and awareness engagement, $\mathrm{p}=0.015$.

Conclusions and recommendations : Around 66 per cent of nurses have experience of birth asphyxia, the study showed. Despite Born Asphyxia, about half of them have strong and optimistic disposition towards Neonate. Education will be deemed to improve nurses' awareness of Neonate with Birth Asphyxia

Key words: Knowledge, Nurses, birth asphyxia.

\section{Itroduction}

Birth asphyxia is neonates' inability to activate and sustain breathing at conception .. It is also recognized as a condition that arises when blood gas delivery is compromised, contributing to hypoxemia and hypercapnia The combination of hypoxia and ischemia may contribute to a cascade of biochemical changes in the body contributing to neuronal brain loss and brain harm ${ }^{(1)}$. According to the (World Health Organization;
2007) Birth asphyxia can occur as a result of factors such as premature lungs with inadequate surfactant for proper functioning. Maternal, placental, or fetal triggers can be involved. Complications such as obesity, disease and drug consumption are motherly triggers Placental disorders such as placenta Previa, placental abruption or post-maturity may trigger asphyxia in utero ${ }^{(2)}$ The fetal asphyxia triggers include complications with the thread, pregnancy, early delivery and multifetal childbirth. 
(Maternal Newborn Foundations) However, if the arterial umbilical cord $\mathrm{pH}$ is $<7$, the neonate is asphyxiated; the Apgar level is 0-3 for longer than 5 minutes; has cognitive signs such as epilepsy, paralysis or hypertension; and multisystem organ failure like cardiovascular failure;, gastrointestinal, hematological, pulmonary, or renal system (3) Relevant risk factors for prenatal asphyxia involve gestational maternal age below 16 or over 35 years. Age 41 years, asthma, prescription substance and alcohol consumption, hypertensive conditions, excessive breakup of the membrane, maternal inflammation, second or third trimester bleeding and $>24$ hours' labour ${ }^{(4)}$ The clinical form of birth asphyxia is persistent hypoxia, hypercapnia, hypo- perfusion, and metabolic acidosis. Birth asphyxia will be treated if the infant has gasping and insufficient respiration or no breathing at one minute, according to the Regional Neonatology Forum of India. It correlates to 3 minute or less of an Apgar ranking ${ }^{(5)}$ All the attendants must also be trained in newborn resuscitation and must have the appropriate equipment ready to resuscitate the newborn infant. Approximately resuscitation equipment is necessary for effective treatment of asphyxia; but, without the use of equipment, asphyxiated babies can be resuscitated. For the event of birth time asphyxia. Newborn mothers should realize the value of interventions which contribute to the prevention of birth asphyxia. Nonetheless, this concern focuses mainly on the treatment of birth asphyxia, which is neonatal resuscitation rather than avoidance.

\section{Methodology}

Study design: A comprehensive research is performed at the Neonatal Intensive Care Unit in Pediatric Hospitals, Babylon Governorate Babylon Teaching Hospital for Maternity and Children, and ALimam Al-sadiq Clinic. Babylon Governorate, Babylon Health Directorate / Iraq.
Study Sample: A randomized random selection of (62) nurse is chosen through use of the approach to chance sampling. The research sample is spread in the Maternal and Children's Neonatal Intensive Care Unit in Pediatric Hospitals at Babylon Governorate Babylon Teaching Hospital and AL-imam Al- sadiq Hospital.

Study Instrument: Data collection tool which comprises the following:

Part I: Socio-demographic profiles of pediatric nurses in the Babel government clinics for newborns with birth asphyxia comprise (9)items and Respiratory structure and roles comprise (6)items.

Part II: Issues for evaluating the awareness of newborns with birth asphyxia include (6) items and reasons, and (4) items at risk for congenital asphyxia.

Part III: Issues for testing nurses on birth asphyxia include (12) objects, clinical symptoms include (2) objects and medical evaluation include (1) item.

Data Collection the Methods: The data were collected using a built-in self-report questionnaire. To get oral consent, the researcher introduced himself to the participants and clarified the intent of the test.

Statistical analysis: Data entry and interpretation were conducted using computer program SPSS version 23 (statistical kit for social sciences), categorical variables were presented as concentrations and percentages, continuous variables were presented as (mean \pm standard deviation). The same Pearson chi square / Fisher check was carried out to establish the relation between categorical variables, In addition, student t-tests were used to evaluate mean discrepancies between classes. The $\mathrm{P}$ value of 0.05 has been considered statistically important

\section{Results}

Table (1): Nurses their Demographic Characteristics

\begin{tabular}{|l|l|l|}
\hline Variable & mean \pm SD & Range \\
\hline Age (year) & $30.47 \pm 8.86$ & $35(19-54)$ \\
\hline Gender & & \\
Male & 38 & $61.3 \%$ \\
Female & 24 & $38.7 \%$ \\
Total & 62 & $100.0 \%$ \\
\hline
\end{tabular}




\begin{tabular}{|l|l|l|}
\hline Marital status & & \\
Single & 16 & $25.8 \%$ \\
Married & 46 & $74.2 \%$ \\
Divorce & 0 & $0.0 \%$ \\
Widow & 0 & $0.0 \%$ \\
Separated & 0 & $0.0 \%$ \\
Total & 62 & $100.0 \%$ \\
& & \\
\hline Educational level & & $17.8 \%$ \\
Preparatory nursing & 11 & $54.8 \%$ \\
Diploma & 34 & $22.6 \%$ \\
Bachelor & 14 & $4.8 \%$ \\
Master & 3 & $100.0 \%$ \\
Total & 62 & \\
\hline
\end{tabular}

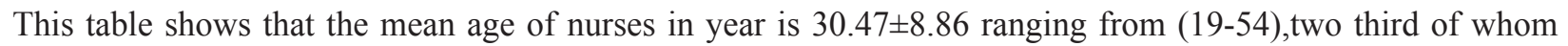
$(61.3 \%)$ are male, $74.2 \%$ of the respondents are married and just over half of them (54.8\%) have a diploma.

table (2): Nurses Knowledge Distribution of mean knowledge of nurse regarding birth asphyxia(n=62)

\begin{tabular}{|l|l|l|l|}
\hline Variable & Mean & Frequency & Percentage(\%) \\
\hline Good knowledge & $\geq 17.85$ & 41 & $66.1 \%$ \\
\hline Poor knowledge & $<17.85$ & 21 & $33.9 \%$ \\
\hline
\end{tabular}

This table shows that the participants with good knowledge represented (66.1\%), while those with

poor knowledge represented $(33.9 \%)$. The overall knowledge were estimated by taking the average score of all subscales ,the subscales score were obtained by summing items score and dividing by the total number of items. Good knowledge is participant who scored above or equal mean for knowledge questions.

Poor knowledge is participant who scored below mean for knowledge questions. Finding reveals that the majority of $(60.7 \%)$ were poor knowledge of nurses at primary health care centers in Babylon Governorate.

Table( 3): Association between variables related to work and training of nurses and knowledge(n=62)

\begin{tabular}{|c|c|c|c|}
\hline \multirow[b]{2}{*}{ Study variables } & \multicolumn{3}{|l|}{ Knowledge } \\
\hline & Good & Poor & p-value \\
\hline $\begin{array}{l}\text { Participation in training course } \\
\text { Yes } \\
\text { No } \\
\text { Total }\end{array}$ & $\begin{array}{l}37(90.2 \%) \\
4(9.8 \%) \\
41(100.0 \%)\end{array}$ & $\begin{array}{l}13(61.9 \%) \\
8(38.1 \%) \\
21(100.0 \%)\end{array}$ & $0.015^{*} \mathrm{~F}$ \\
\hline $\begin{array}{l}\text { If yes, type of training }(\mathrm{n}=50) \\
\text { Theoretical } \\
\text { Practical } \\
\text { Both } \\
\text { Total }\end{array}$ & $\begin{array}{l}9(24.3 \%) \\
6(16.2 \%) \\
22(59.5 \%) \\
37(100.0 \%)\end{array}$ & $\begin{array}{l}3(23.1 \%) \\
0(0.0 \%) \\
10(76.9 \%) \\
13(100.0 \%)\end{array}$ & $0.402^{\mathrm{F}}$ \\
\hline
\end{tabular}




\section{Cont... Table (1): Nurses their Demographic Characteristics}

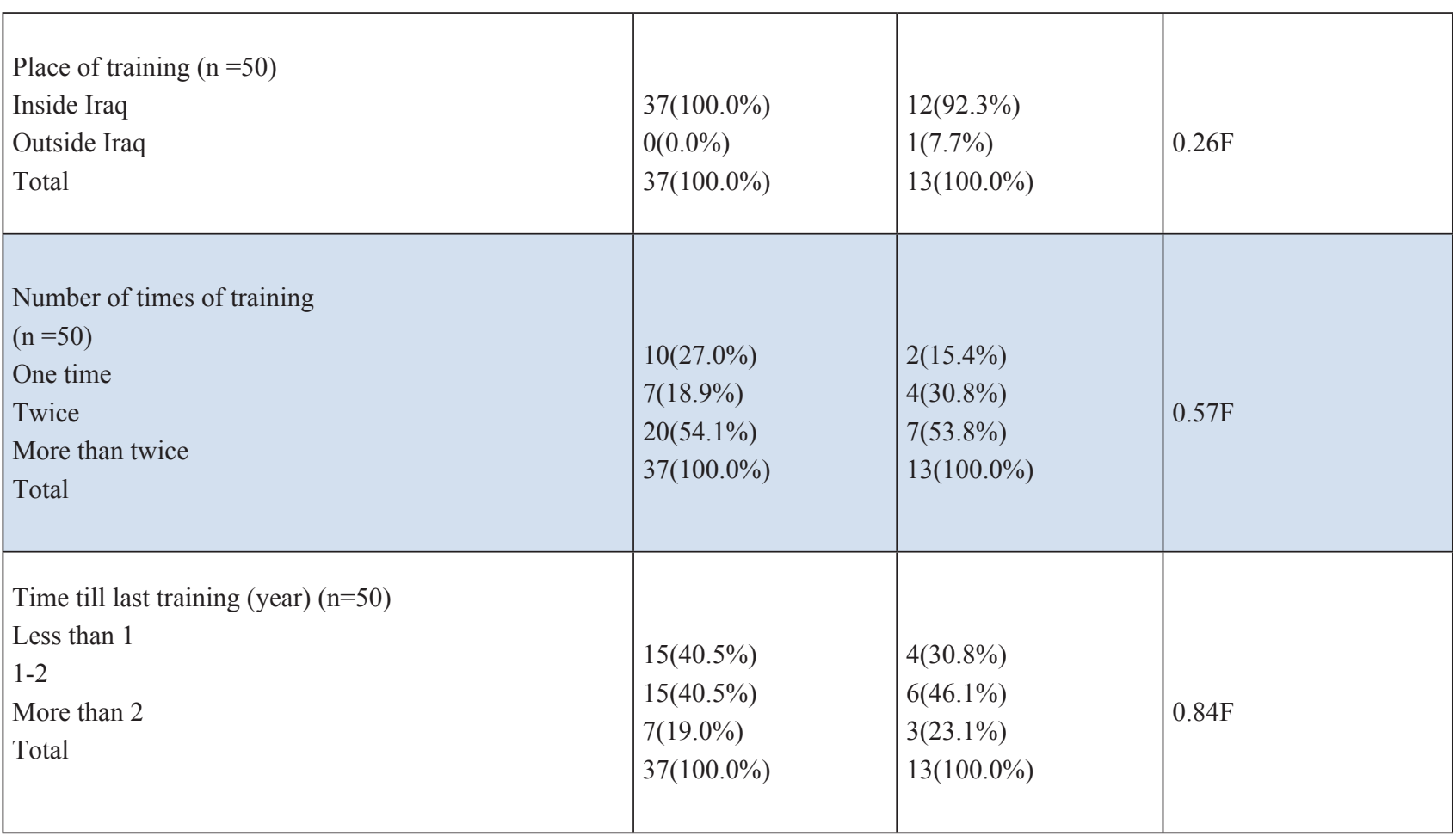

\section{*P value $\leq 0.05$ was significant,$F$ : Fisher exact test}

Table (3)shows that Fisher exact test was conducted to show an association between variables related to work and training of nurses and knowledge regarding birth asphyxia (good or poor).

There is significant association between participation in training course and knowledge, $\mathrm{p}$ value $=0.015$.

\section{Discussion}

Part I: Discussion the demographic characteristics

Our results reflect the concise data of the sociodemographic details of the nurses who function in frequency and percentage terms in the neonatal intensive care unit. Of the (62) participants that took part in this research, their age distribution of nurses in the year was $30.47 \pm 8.86$, varying from (19-54), two-thirds of which $(61.3 \%)$ were male, $(54.8 \%)$ had a certificate, (22.6\%) had a Bachler, , (4.8\%) had a master's degree According to their professional success, most nurses (54.8\%) graduated with a nursing certificate, since the credential was deemed to be the highest percentage of staff nurses in a health system regardless of the vast number of establishments graduating with that degree.
This statement also came from the pediatric hospitals' neonatal intensive care unit We are largely reliant on nurses who have graduated from nursing and high school while nurses that have graduated from nursing college are assigned to specific units of hospitals and are only in low numbers compared with other patients.

$74.2 \%$ of respondents are dating and only over half are female as the bulk of these age ranges are dating., especially after the conclusion of the nursing studies and appointments. Where the Iraqi young take advantage of the marriage hand after graduation from the study and the availability of work opportunities. Mean years of clinical practice varied from (1-22) $7.77 \pm 4$.94. Third (80.6\%) took part in educational or academic classes, nearly exclusively inside Iraq (98.0\%). 38.0 percent of nurses indicated that the last time they provided infant resuscitation instruction was the previous year, this finding was followed by a survey carried out of Awareness Evaluation, Birth asphyxia treatment mindset and experience at the Federal Medical Center Asaba, Delta State-Nigeria. Their analysis shows that $16(32 \%)$ of the respondents have at least one neonatal resuscitation experience while $3(6 \%)$ have two experience cycles. $3(6 \%)$ had less than a year earlier, 7 
(14\%), 2 (4\%) and 5 (10\%) had their last schooling from 1-2 years, 3-4 years.. And 12(0) appropriately for 1-5, 6-10, 11-15, 16-20 and 21-30. With regard to experience in neonatal resuscitation, respondents ranked 9.6 (2.9) and 10.1 (2.3) respectively for those with and without experience $^{(6)}$

\section{Part II: Discussion the nurses knowledge}

The result indicates that participants with good information identified (66.1 per cent) strong information are participants who ranked at or equivalent mean for questions of knowledge. This finding is followed by a research conducted to determine the efficacy of a formal training system on information regarding neonatal asphyxia control among staff nurses in pediatric allied units in selected hospitals of Punjab According to this report, $24(80 \%)$ respondents had strong information, $2(6.67 \%)$ had great knowledge and $4(13.33 \%)$ had outstanding knowledge in the experimental category and $23(76.67 \%)$ respondents had acceptable knowledge and $7(23.33 \%)$ had less than average knowledge in the control group ${ }^{(7)}$.

Weak information (33.9 per cent) was reflected. Participants who ranked below mean for information questions are followed by a test performed in Evaluation of Information of Birth Asphyxia in staff nurses employed in the workplace and NICU Results of this research $5(16.67 \%)$ had weak awareness ${ }^{(8)}$.

Part III: Discussion the relationship between variables related to work and training of nurses and knowledge

Findings indicate the connection of information linked to birth asphyxia among nurses and their demographic characteristics. There is a strong correlation between involvement in training and information, $\mathrm{p}$ value $=0.015$ This finding fits the test findings obtained in a cross-sectional analysis obtained in Nigeria Education. Health care professionals, so they should boost their capacity to provide patient treatment. It will also improve the capacity and their awareness to control birth asphyxia. Just 29.4 percent of nurses have been qualified in the new research. This result was comparable with the result in the analysis in Kenya that only $23 \%$ of the test participants provided training ${ }^{(9)}$.

\section{Conclusions}

In terms of awareness, birth asphyxia was bad awareness among nurses. Nurses years of neonatal intensive care unit practice and preparation programs play an significant part in their expertise. To develop awareness, it requires to hire comprehensive educational courses relevant to birth asphyxia and neonate resuscitation.

\section{Ethical Clearance}

The Research Ethical Committee at scientific research by ethical approval of both $\mathrm{MOH}$ and MOHSER in Iraq

\section{Conflict of Interest: Non}

Funding: Self-funding

\section{References}

1- Lawn JE, Cousens S, Zupan J. 4 million neonatal deaths: when? Where? Why? Lancet. 2005; 365(9462):891- 900.

2- Lawn J, Kerber K. Opportunities for Africa newborns: practical data policy and programmatic support for newborn care in Africa. South Africa: Partnership for Maternal, Newborn and Child Health; 2006.

3- de Souza ALS, de Souza NL, de França DF, et al. Risk factors for perinatal asphyxia in newborns delivered at term. Open Journal of Nursing. 2016;6(07):558 .

4- Kim, E.T., Singh, K., Speizer, I.S. et al. Availability of health facilities and utilization of maternal and newborn postnatal care in rural Malawi. BMC Pregnancy Childbirth 2019: 19, 503. 6-88.

5- Lee AC, Cousens S, Wall SN et al. . Neonatal resuscitation and immediate newborn assessment and stimulation for the prevention of neonatal deaths: a systematic review, meta-analysis and Delphi estimation of mortality effect. BMC Public Health 2011;11(Suppl 3):S12

6- Murila F, Obimbo MM, Musoke R. Assessment of knowledge on neonatal resuscitation amongst health care providers in Kenya. Pan African Medical Journal. 2012; 11(11): 78.

7- Munthali AC, Mannan H, MacLachlan M, Swartz L, Makupe CM, Chilimampunga C. Non-use of Formal Health Services in Malawi: Perceptions from Non-users. Malawi Med J. 2014;26(4):12632. 
8- kiles MP, Burgert CR, Curtis SL, Spencer J. Geographically linking population and facility surveys: methodological considerations. Popul
Health Metrics. 2013;11:14.

9- Strasser R. Rural health around the world: challenges and solutions. Fam Pract. 2003;20(4):457-63. 